\title{
Simulating Building Motions Using Ratios of the Building's Natural Frequencies and a Timoshenko Beam Model
}

\author{
Ming Hei Chenga) M.EERI, and Thomas H. Heaton ${ }^{a)}$ M.EERI
}

\begin{abstract}
A simple prismatic Timoshenko beam model with soil-structure interaction (SSI) is developed to approximate the dynamic linear elastic behavior of buildings. A closed-form solution with complete vibration modes is derived. It is demonstrated that building properties, including mode shapes, can be derived from knowledge of the natural frequencies of the first two translational modes in a particular direction and from the building dimensions. In many cases, the natural frequencies of a building's first two vibrational modes can be determined from data recorded by a single seismometer. The total building's vibration response can then be simulated by the appropriate modal summation. Preliminary analysis is performed on the Caltech Millikan Library, which has significant bending deformation because it is much stiffer in shear. [DOI: 10.1193/ 011613EQS003M]
\end{abstract}

\section{INTRODUCTION}

The use of seismic data in buildings to study the deformations of a structure is a wellestablished research area in earthquake engineering (e.g., Skolnik et al. 2006, Kohler et al. 2007, Krishnan and Muto 2013). Ideally, several stations are established in locations that can best describe the spatial/temporal pattern of building motions. However, a new type of seismic network is under development-crowd-sourced seismic networks where volunteers install the seismometers. Examples include the Quake Catchers Network (Cochran et al. 2011) and the Community Seismic Network (Clayton et al. 2011). In a crowd-sourced network, station locations are typically chosen for reasons that are unrelated to optimal seismic network design. In particular, there may be instances in which a single seismometer is the only record that is available from a building. Furthermore, it may not be practical to construct a detailed finite-element model of the building; even if there are sufficient resources to construct a dynamic model, the building's structural design may not be available. However, if the geometry of the building is known (e.g., obtained from Google Earth), it may be feasible to infer its approximate deformations using only a single seismic station. Seismologists have inferred the radial structure of the Earth using models that predict the frequencies of its normal modes (e.g., He and Tromp 1996, Rosat et al. 2007, and Romanowicz et al. 2008). These frequencies are the same at all stations; that is, knowledge of the modal frequencies recorded at a single station is sufficient to infer the radial properties of a spheroid. This paper presents a simple methodology for obtaining the approximate motions of a building based on at least one seismogram and knowledge of the building's geometry (especially the height).

\footnotetext{
a) Department of Mechanical and Civil Engineering, California Institute of Technology, Pasadena, CA
} 
Although buildings primarily consist of structural members (columns, walls, floors, etc.) separated by void spaces (rooms, doors, windows, etc.), large-scale deformation of a structure can often be approximately described by an equivalent homogeneous elastic continuum. In particular, many aspects of building motions can be understood in the context of a simple cantilevered elastic beam on an elastic half-space (i.e., the Earth). The strains that develop at the interface between the beam and the half-space are quite complex. Fortunately, it is possible to develop methodologies to approximately model the mechanics of a cantilevered beam. The simplest approximation is to consider a beam that responds only in shear (e.g., Westergaard 1933, Jennings and Newmark 1960, and Iwan 1997), often referred to as a shear beam. A shear beam is basically the same problem as a uniform layer on a half-space that is subject only to horizontal shear tractions. The effective density of the building can be calculated from an estimate of the building mass and total volume. The effective shear wave velocity in the building is $4 L f_{1}$, where $L$ is the building height and $f_{1}$, where $L$ is the frequency of the first (fundamental) mode.

As a beam becomes very narrow compared to its length, deformation primarily occurs as bending - that is, contraction on one side of the beam and extension on the opposite side. Much is known about the technical theory of bending, which relates the bending moment on a beam to the bending displacements of the beam. If shear deformations are negligible, a beam can be simulated using the Bernoulli-Euler equation, which relates fourth-order spatial derivatives of horizontal deflections to horizontal forces and inertial accelerations (e.g., Foutch and Jennings 1978). Unlike shear waves, which have frequency-independent wave velocities, bending waves are inherently dispersive; higher frequencies have higher wave speeds. Although interstory shearing (Figure 1a) is the primary deformation mode of buildings that are wide in relation to their height, tall and thin buildings may experience significant bending (Figure 1b). This is especially true if the building has high shear stiffness, which is the case for Caltech's Millikan Library, which has extensive shear walls. Models ignoring the effect of flexural deformation may cause noticeable errors. However, pure flexural models are rarely appropriate, even for buildings with high effective rigidity [e.g., shear walls as the

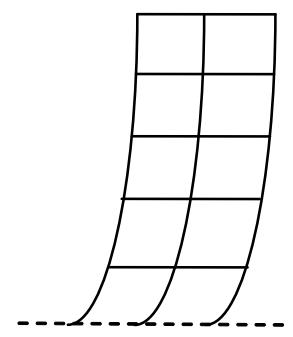

(a)

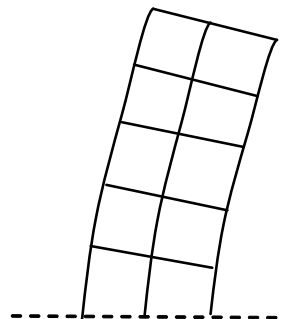

(b)

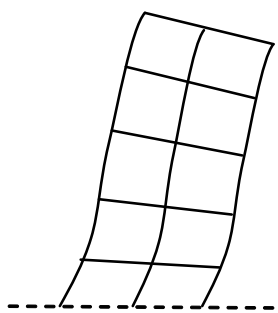

(c)

Figure 1. Building deformation (a) shear-beam behavior (vertically propagating SH-waves) is expected when shear stiffness is less than flexural stiffness; (b) bending-beam behavior (Bernoulli-Euler beam equation) is expected for tall and narrow buildings (small flexural stiffness); (c) combined shearing and bending known as a Timoshenko beam. 
main lateral load-resisting systems (Miranda 1999)]. In reality, a building deforms in a mixture of flexural and shearing deflections (Figure 1c).

Because of the deficiencies of simple pure-shear or pure-flexural models, researchers began using more complex models that incorporated more general building responses. In particular, a Timoshenko beam (Timoshenko 1937, Timoshenko and Goodier 1951, Heidebrecht and Smith 1973, and Rahgozar et al. 2004) is a computational model with differential equations coupling the effects of a shear beam and a bending beam, with the constraint that total deflections are caused by the sum of the shear deformations and the flexural deformations. Miranda (1999) used a continuum structural model consisting of a flexural cantilever beam and a flexural shear beam to predict deformations in buildings. He assumed the particular case of a Timoshenko for which the roof deformations from flexure and shear were equal. Boutin et al. (2005) and Michel et al. (2006) suggested that mode shapes could be retrieved from the ratio of the first two natural frequencies of a building using a fixed-base Timoshenko beam model, but they ignored section rotation inertia and soil-structure interaction. Soil-structure interaction can significantly affect the natural frequencies of a building. A simple consideration of the first two recorded natural frequencies of the system may lead to misinterpretation of the properties of a fixed-base Timoshenko beam. Dynamic Timoshenko beam models are used in other engineering applications. For example, they are widely applied in the simulation of micro- or nanobeams (e.g., Hsu et al. 2007, Wang et al. 2007).

In this paper, a simple prismatic Timoshenko beam model with soil-structure interaction (SSI) is developed to approximate the dynamic linear elastic behavior of buildings. A closedform response solution with complete vibration modes is derived. Once the dimensions of the building are specified, the building properties, including mode shapes, can be derived by knowing the ratios of the frequencies of the first two normal modes in a particular direction. In many instances, the natural frequencies of the first two vibrational modes of a building can be identified by spectral analysis of data from a single seismometer. If the modes and mode shapes are known, the excitation of each mode can be determined from analysis of a single building record. The entire spatial/temporal building vibration response can then be approximated by the appropriate modal summation. Preliminary analysis is performed on Caltech's Millikan library, which has high shear stiffness and so bending makes up a significant part of the overall deformation.

\section{TIMOSHENKO BEAM MODEL WITH SOIL-STRUCTURE INTERACTION}

A multistory building can be modeled as an equivalent prismatic homogeneous Timoshenko beam with SSI, as shown in Figure 2. The building has a flexural rigidity of $E^{*} I$, where $E^{*}$ is an effective Young's modulus and $I$ is the second areal moment about the neutral axis of bending (horizontal in this case). $E^{*}$ is typically much lower than the intrinsic $E$ of the structural materials because building volume comprises mostly air. Because bending obeys a fourth-order differential equation, the beam's overall flexural stiffness decreases rapidly with its increasing length; that is; flexural stiffness is defined as $E^{*} I / L^{3}$, where $L$ is the building height.

The effective shear modulus of the building is $G^{*}$ and it is useful to compare overall building stiffness with soil stiffness to assess the importance of the soil-structure interaction. In this case, $G^{*}$ can be much lower than the $G$ of the building materials. In particular, 


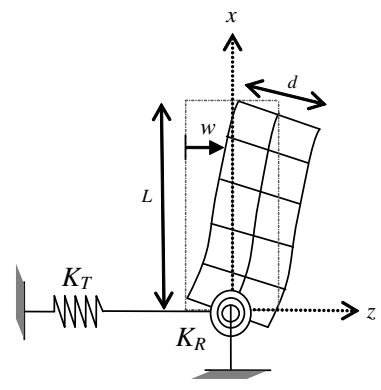

Building:

Flexural stiffness $\frac{E^{*} I}{L^{3}}$

Shear stiffness $\frac{k G^{*} A}{L}$

Figure 2. Timoshenko beam with soil-structure interaction. Horizontal spring $K_{T}$ simulates the difference in horizontal ground motion of the building base caused by the inertial forces of the building on the ground. This effect is typically minor because the average density of the building is small compared to the ground. The rotational spring $K_{R}$ simulates the rocking rotation of the base of the building.

moment-resisting frame buildings are often designed to be flexible in shear, in which case $G^{*}$ can be very small. The overall shear stiffness of the building is defined as $k G^{*} A / L$, where $A$ is the cross-sectional area and $k$ is the shear factor (to adjust for different cross-sectional shapes: $k=(2 / 3)$ for a rectangular cross section). The building considered here is assumed to have uniform stiffness and mass along its height and remains linearly elastic. The effect of the soil is to cause horizontal motions of the building's base and rocking about a horizontal axis. To simulate the effect of the soil-structure interaction, a translational spring with stiffness $K_{T}$ and a rotational spring with stiffness $K_{R}$ are incorporated at the base of the building. Balendra et al. (1982) studied the responses of a linear $N$-story shear building sitting on an elastic homogeneous half-space and showed that $K_{T}$ and $K_{R}$ can be estimated from the soil properties; that is,

$$
K_{T}=\frac{32(1-v)}{7-8 v} G_{\text {soil }} r_{o} \quad \text { and } \quad K_{R}=\frac{8}{3(1-v)} G_{\text {soil }} r_{o}^{3}
$$

where $G_{\text {soil }}$ is the shear modulus of the soil, $v$ is Poisson's ratio of the soil, and $r_{o}$ is the equivalent radius of the foundation.

Given the flexural stiffness and shear stiffness of a building, together with the soil spring stiffness, a closed-form free vibrational response is expressed as follows (the derivation is given in the Appendix):

$$
w=C_{1} \cosh \left(\alpha \frac{x}{L}\right)+C_{2} \sinh \left(\alpha \frac{x}{L}\right)+C_{3} \cos \left(\beta \frac{x}{L}\right)+C_{4} \sin \left(\beta \frac{x}{L}\right)
$$

where $w$ is the horizontal deflection and $x$ is the distance along the vertical axis. The values $\alpha$ and $\beta$ depend on the building's natural frequencies $\omega$.

Using the characteristic equation derived in the online Appendix, the natural frequency ratios of the one-dimensional Timoshenko beam with SSI can be determined with different shear stiffness-to-flexural stiffness ratios $r$ : 


$$
\begin{aligned}
r & =\frac{\text { shear stiffness }}{\text { flexural stiffness }}=\frac{\frac{k G^{*} A}{L}}{\frac{E^{*} I}{L^{3}}}=\frac{k G^{*} A L^{2}}{E^{*} I} \\
& =\frac{8 G^{*} L^{2}}{E^{*} d^{2}} \text { for rectangular cross- section with } k=\frac{2}{3}
\end{aligned}
$$

To investigate the dynamic behavior of buildings on different soil conditions, three soil types with shear wave velocities $V_{S}$ of $60 \mathrm{~m} / \mathrm{s}$ (very soft), $300 \mathrm{~m} / \mathrm{s}$ (stiff), and $1,000 \mathrm{~m} / \mathrm{s}$ (fixed base) are chosen. Soil with shear wave velocity $V_{s}=60 \mathrm{~m} / \mathrm{s}$ is considered the very soft end of soft soil. In practice, buildings typically will not be constructed on such soil. This study considers this very soft soil to investigate the effect of the soil-structure interaction. Other parameters are arbitrarily chosen based on the values estimated for the Millikan Library building (described in a later section). The study investigates how model parameters, including building height $L$, stiffness ratio $r$, and building density $\rho_{\text {building }}$, are related to natural frequency ratios. The sensitivity analysis assumes the effective shear modulus of the building to be

$$
G^{*}=\rho_{\text {building }}\left(4 L f_{1}\right)^{2}=\rho_{\text {building }}\left(4 L \frac{30}{L}\right)^{2}=14,400 \rho_{\text {building }}
$$

where a story height of $3 \mathrm{~m}$ is used and a fundamental period of $1 \mathrm{~s}$ is assumed for every 10 stories (i.e., $f_{1}=30 / L$ ). It is assumed that building densities, $\rho_{\text {building }}$, are on the order of $200 \mathrm{~kg} / \mathrm{m}^{3}$ for light and flexible frame buildings and $400 \mathrm{~kg} / \mathrm{m}^{3}$ for heavy, stiff shear wall buildings. The aspect ratio of a building is defined as $L / d$. The values used in this analysis are listed in Table 1.

The natural frequency ratio of the $i$ th mode is defined as $f_{i} / f_{1}$. In this study, the proposed

\begin{tabular}{|c|c|c|c|}
\hline s-wave velocity $V_{s}$ & $\begin{array}{c}60 \mathrm{~m} / \mathrm{s} \\
\text { (very soft soil) }\end{array}$ & $\begin{array}{l}300 \mathrm{~m} / \mathrm{s} \\
\text { (stiff soil) }\end{array}$ & $\begin{array}{c}1,000 \mathrm{~m} / \mathrm{s} \\
\text { (fixed base) }\end{array}$ \\
\hline Soil density $\rho_{\text {soil }}$ & & $1,850 \mathrm{~kg} / \mathrm{m}^{3}$ & \\
\hline Poisson's ratio $v$ & & 0.33 & \\
\hline Building depth $d$ & & Varies & \\
\hline Building height $L$ & & Varies & \\
\hline Building density $\rho_{\text {building }}$ & & $200 \mathrm{~kg} / \mathrm{m}^{3}$ or $400 \mathrm{~kg} / \mathrm{m}^{3}$ & \\
\hline Equivalent foundation radius $r_{o}$ & & $12.4 \mathrm{~m}$ & \\
\hline Soil shear modulus $G_{\text {soil }}$ & $6.67 \times 10^{6} \mathrm{~Pa}$ & $1.67 \times 10^{8} \mathrm{~Pa}$ & $1.85 \times 10^{9} \mathrm{~Pa}$ \\
\hline Soil translational stiffness $K_{T}$ & $4.06 \times 10^{8} \mathrm{~N} / \mathrm{m}$ & $1.02 \times 10^{10} \mathrm{~N} / \mathrm{m}$ & $1.13 \times 10^{11} \mathrm{~N} / \mathrm{m}$ \\
\hline Soil rotational stiffness $K_{R}$ & $5.05 \times 10^{10} \mathrm{Nm}$ & $1.26 \times 10^{12} \mathrm{Nm}$ & $1.40 \times 10^{13} \mathrm{Nm}$ \\
\hline Effective shear modulus $G^{*}$ & & $14,400 \rho_{\text {building }} \mathrm{Pa}$ & \\
\hline Stiffness ratio $r$ & & Varies & \\
\hline Effective Young's modulus $E^{*}$ & & Varies & \\
\hline
\end{tabular}
method focuses on the frequency ratios estimated using the Timoshenko beam. A pure shear

Table 1. Parameter study for Timoshenko beam model 
beam with a rigid base exhibits its first three natural frequency ratios as 1, 3, and 5, whereas a pure bending beam with a rigid base exhibits its first three natural frequency ratios as $1,6.27$, and 17.55. With the effect of the soil-structure interaction, the frequency ratio $f_{2} / f_{1}$ is not necessarily bounded between 3 (pure shear building on a fixed base) and 6.27 (pure bending building on a fixed base) (see Figure 3, which is explained in the next paragraph). Timoshenko beams that have the same ratios between flexural stiffness, shear stiffness, and soil stiffness exhibit the same frequency ratios; that is, the frequency ratios are only functions of the stiffness ratios and the dimensions of the building - given the height and the aspect ratio of the building, the stiffness ratio between shearing, bending, and soil can be determined from the ratios of the normal mode frequencies.

Figure 3 describes the effect of building height $L$ on the frequency ratio $f_{2} / f_{1}$ for a lightweight frame building with a building density $\rho_{\text {building }}=200 \mathrm{~kg} / \mathrm{m}^{3}$, a fixed effective shear modulus $G^{*}=2.88 \mathrm{MPa}$, and a fixed stiffness ratio $r=20$. The result shows that building height has negligible effect on frequency ratio for flexible buildings with a fixed base. A taller building induces a larger frequency ratio $f_{2} / f_{1}$ for buildings on very soft soil because of the soil-structure interaction effect, and this effect is more significant on a small aspect ratio $L / d$. For example, the frequency ratio $f_{2} / f_{1}$ can increase from about 4.0 to 10.3 for a building with $L=150 \mathrm{~m}$ and $L / d=2$ sitting on soft soil.

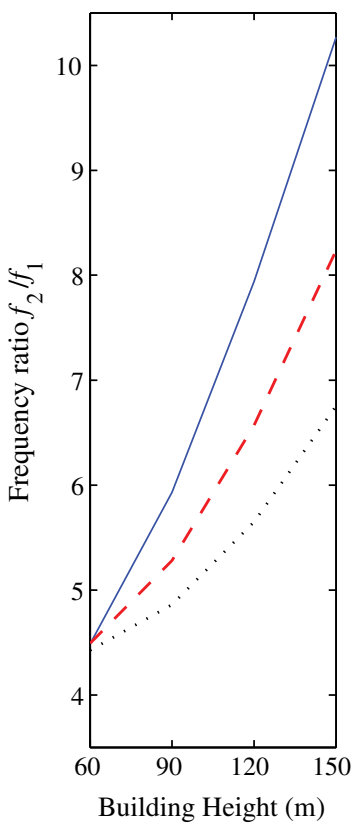

(a)

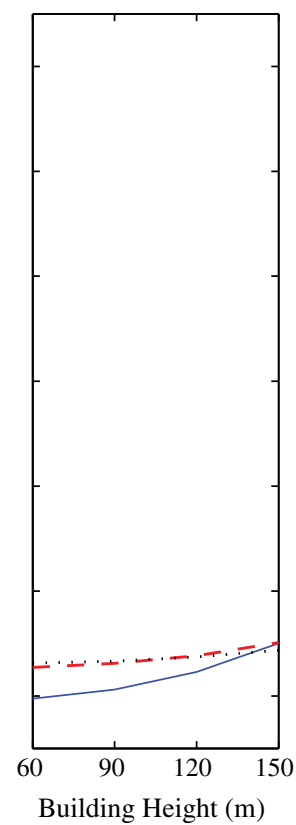

(b)

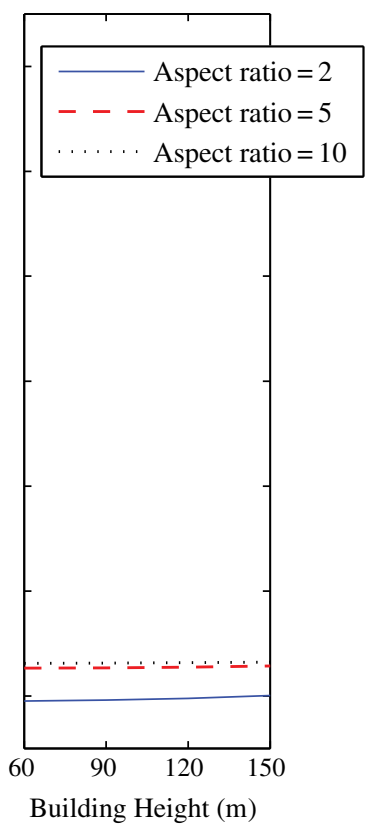

(c)

Figure 3. Effect of building height on frequency ratio $f_{2} / f_{1}$ : (a) very soft soil $\left(V_{s}=60 \mathrm{~m} / \mathrm{s}\right)$; (b) stiff soil $\left(V_{S}=300 \mathrm{~m} / \mathrm{s}\right)$; (c) fixed base $\left(V_{S}=1,000 \mathrm{~m} / \mathrm{s}\right)$. Effective shear modulus of the building $G^{*}=2.88 \mathrm{MPa}$ and stiffness ratio $r=20$ are fixed. The aspect ratio is the building height divided by its width. 
Figure 4 (light, flexible frame buildings, $\rho_{\text {building }}=200 \mathrm{~kg} / \mathrm{m}^{3}$ ) and Figure 5 (heavy, stiff shear wall buildings, $\rho_{\text {building }}=400 \mathrm{~kg} / \mathrm{m}^{3}$ ) describe the effect of stiffness ratio $r$ on the frequency ratio. In this case, a building height of $60 \mathrm{~m}$ and a building effective shear modulus $G^{*}=14,400 \rho_{\text {building }}$ are used. A Timoshenko beam with a small $r(r=0.1)$ behaves like a pure shear beam, whereas a fixed-base Timoshenko beam with a large $r(r=1,000)$ does not necessarily behave like a pure bending beam. The results show that the frequency ratio of the Timoshenko beam matches that of a pure bending beam only when it has a large aspect ratio $(L / d=10)$, which confirms that a building performs similarly to a pure bending beam only when it is relatively tall and narrow. A point to note is that Miranda and Taghavi (2005) define a similar stiffness ratio $r$ in their coupled shear wall frame structure, but their model behaves like a shear beam for large $r$ and a bending beam for small $r$. Dym and Williams (2007) explain such a difference as being due to the fact that the Timoshenko beam couples the shear and flexural stiffnesses in series but Miranda's model couples them in parallel.

Comparing the frequency ratio of a building sitting on very soft soil to one on a fixed base suggests that the soil-structure interaction has a significant effect on shear-type buildings but has a minimal effect on pure bending structures. In Figures 4 and 5, it is seen that frequency ratio $f_{2} / f_{1}$ is amplified only for regions with stiffness ratio $r<50$, which represents buildings with considerable shear-type behavior. Also, the amplification is more significant

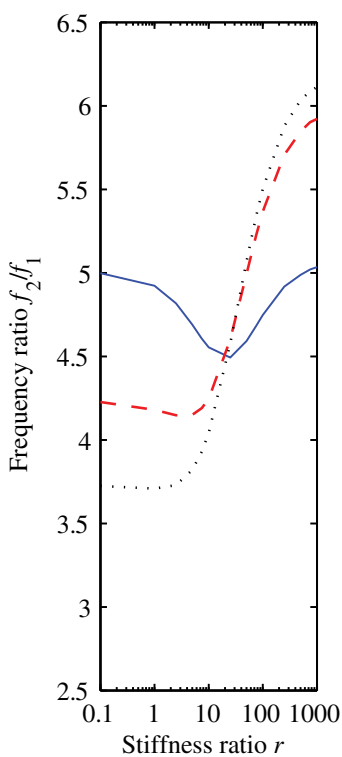

(a)

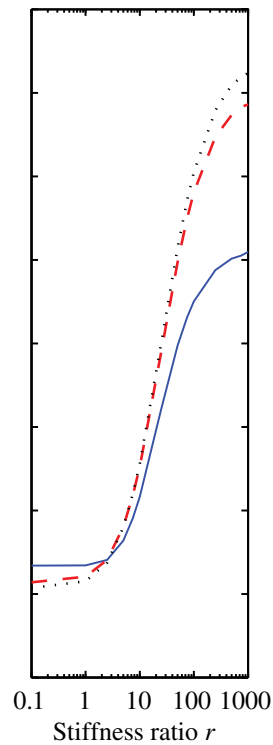

(b)

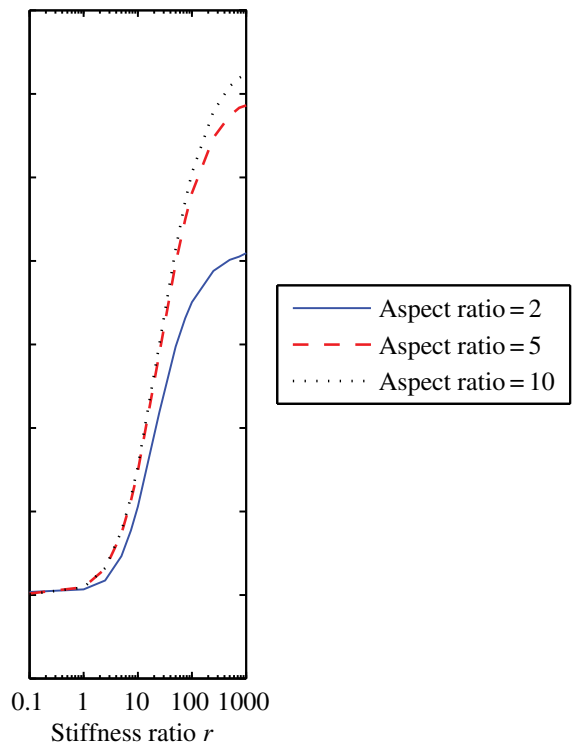

(c)

Figure 4. Effect of stiffness ratio $r$ (shear stiffness/flexural stiffness) on the frequency ratio of buildings with $\rho_{\text {building }}=200 \mathrm{~kg} / \mathrm{m}^{3}$ (light and flexible frame): (a) very soft soil $\left(V_{S}=60 \mathrm{~m} / \mathrm{s}\right.$ ); (b) stiff soil $\left(V_{S}=300 \mathrm{~m} / \mathrm{s}\right)$; (c) fixed base $\left(V_{S}=1,000 \mathrm{~m} / \mathrm{s}\right)$. Effective shear modulus of the building $G^{*}=2.88 \mathrm{MPa}$ and building height $L=60 \mathrm{~m}$ are fixed. The aspect ratio is the building height divided by its width. 


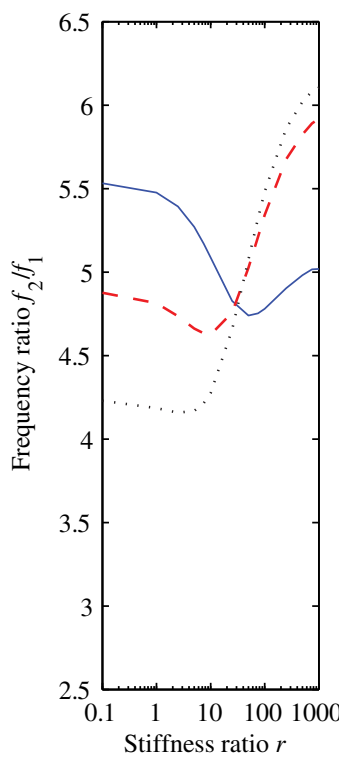

(a)

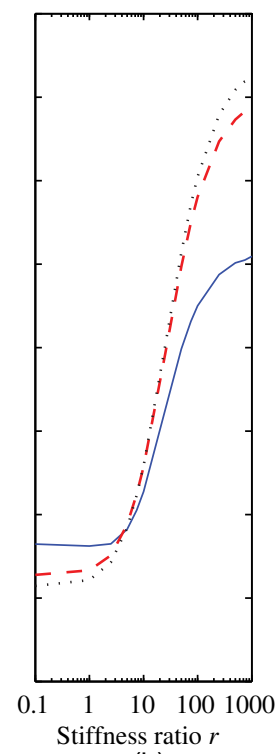

(b)

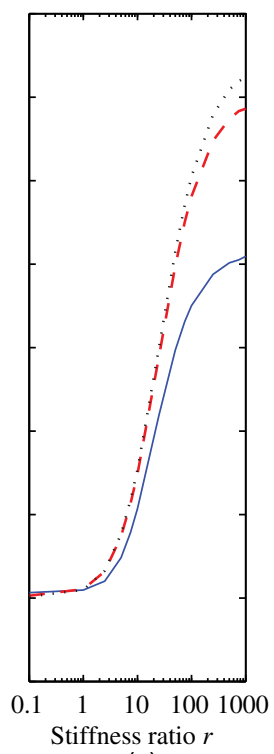

(c)

Figure 5. Effect of stiffness ratio $r$ (shear stiffness/flexural stiffness) on the frequency ratio of buildings with $\rho_{\text {building }}=400 \mathrm{~kg} / \mathrm{m}^{3}$ (heavy, stiff shear wall). (a) very soft soil $\left(V_{S}=60 \mathrm{~m} / \mathrm{s}\right.$ ); (b) stiff soil $\left(V_{S}=300 \mathrm{~m} / \mathrm{s}\right)$; (c) fixed base $\left(V_{S}=1,000 \mathrm{~m} / \mathrm{s}\right)$. Effective shear modulus of the building $G^{*}=5.76 \mathrm{MPa}$ and building height $L=60 \mathrm{~m}$ are fixed. The aspect ratio is the building height divided by its width.

on buildings with higher densities $\rho_{\text {building }}$ and smaller aspect ratios. For example, the frequency ratio $f_{2} / f_{1}$ of a Timoshenko beam with an aspect ratio $=2$ increases from 3 to 5 for a change from fixed base to very soft soil for the light, flexible building with $\rho_{\text {building }}=200 \mathrm{~kg} / \mathrm{m}^{3}$; it increases to 5.5 for the heavy, stiff building $\rho_{\text {building }}=$ $400 \mathrm{~kg} / \mathrm{m}^{3}$. This is similar to the phenomenon reported by Gajan et al. (2010) that foundation displacement and rotation are relatively small compared to the structural deformation in highly flexible structural systems (e.g., bending-type buildings) and so the effect can be neglected; however, the soil-structure interaction has a significant effect on stiff structural systems (e.g., shear-type buildings).

Stewart and Fenves (1998) suggest that the soil-structure interaction predominantly affects the fundamental mode frequency, and this observation agrees with the present numerical study. Figure $6 \mathrm{a}$ shows that the frequencies of a Timoshenko beam with $L=60 \mathrm{~m}, L / d=5, \rho_{\text {building }}=200 \mathrm{~kg} / \mathrm{m}^{3}$, and $r=0.1$ (shear-type building) are reduced by $35.7 \%, 9.7 \%$, and $5.4 \%$, respectively for the first, second, and third modes with a change from fixed base to very soft soil. The percentage of frequency reduction becomes relatively the same at about $6 \%$ for $r=50$, and such an effect is negligible for $r=1,000$ (bending-type building). This study also investigates the effect of soil rotational spring stiffness $K_{R}$ and soil translational spring stiffness $K_{T}$ on frequency change. As shown in Figure $6 \mathrm{~b}, K_{R}$ has a significant effect on the first mode frequency but a minimal effect on the higher modes. 


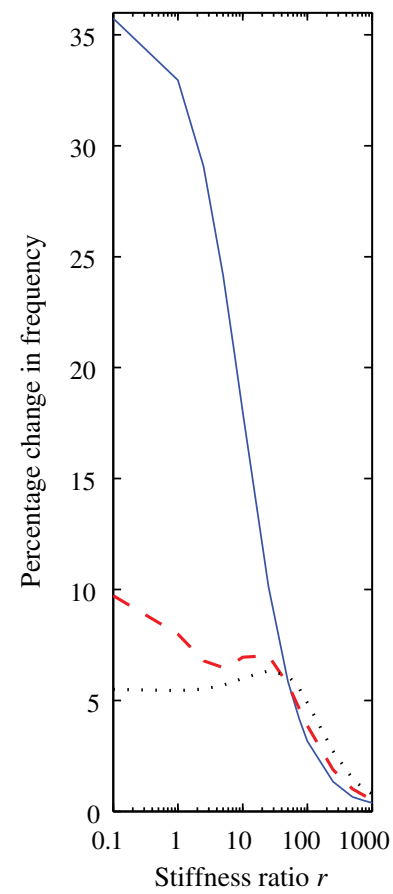

(a)

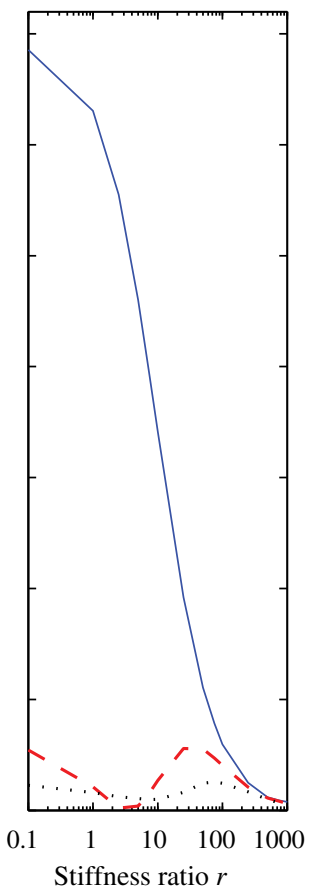

(b)

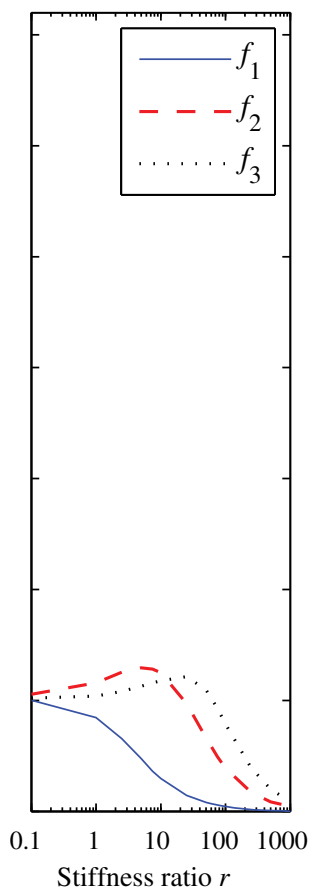

(c)

Figure 6. Effect of stiffness ratio $r$ on the percentage change in frequency of the first three modes: (a) very soft soil $\left(V_{S}=60 \mathrm{~m} / \mathrm{s}\right)$ with soil translational and rotational springs; (b) very soft soil with soil rotational spring only; (c) very soft soil with soil translational spring only. Effective shear modulus of the building $G^{*}=2.88 \mathrm{MPa}$, building height $L=60 \mathrm{~m}$, and aspect ratio $L / d=5$ are fixed.

In contrast, $K_{T}$ in general has less than a $3 \%$ effect. In the combined situation, the frequency change is mostly contributed by $K_{R}$. It is important to understand that the soil's effect on the horizontal motion of the base of the building is rather minor. That is, the horizontal motion of the ground at the base of the building does not change much compared to the horizontal motion of the ground without a building. However, the rotation of the base of the building during rocking causes the forces in the building to differ significantly from those for a building without rocking.

As mentioned, the soil-structure interaction has a major effect on the fundamental mode. Table 2 describes the effect of soil type and building type on the percentage change in fundamental frequency $f_{1}$. Some existing buildings are constructed on soft soil with $V_{S}=150 \mathrm{~m} / \mathrm{s}$ (e.g., Kohler et al. 2005), and maximum change in fundamental frequency corresponds to 9.5\% for shear-type buildings. In general, buildings behave like a Timoshenko beam with properties between a pure shear beam and a pure bending beam, so the soil-structure interaction should not be neglected in determining the dynamic behavior of buildings during earthquakes. 
Table 2. Effects of soil type (shear wave velocity $V_{S}$ ) and building type (stiffness ratio $r$ i.e., shear stiffness/flexural stiffness) on percentage change in fundamental frequency $f_{1}$

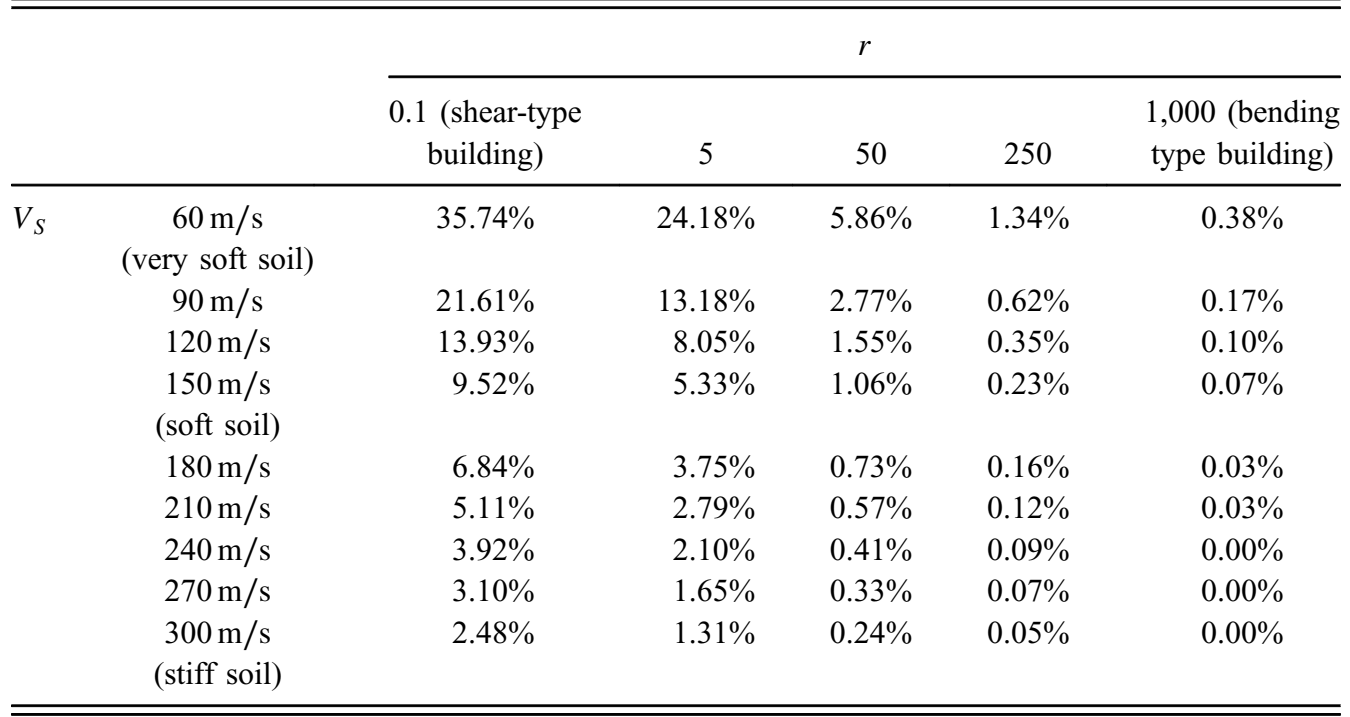

\section{BUILDING SYSTEM IDENTIFICATION}

The following steps are taken to simulate the spatial/temporal dynamic behavior of an existing building:

1. Estimate the soil's s-wave velocity $V_{S}$, density $\rho_{\text {soil }}$, and Poisson's ratio $v$.

2. Estimate the building's dimensions (width $d$ and height $L$ ), which can usually be approximated using Google Earth; underground substructures usually contain thick and stiff shear walls, so they have minimal effect on the building's deflection; $L$ can be roughly approximated as the height above ground.

3. Estimate the building's density $\rho_{\text {building }}$, which can be approximated from the building's structural type; assume that building densities are on the order of $200 \mathrm{~kg} / \mathrm{m}^{3}$ for light, flexible frame buildings and $400 \mathrm{~kg} / \mathrm{m}^{3}$ for heavy, stiff shear wall buildings.

4. Determine the building's first two natural frequencies $\left(f_{1}\right.$ and $\left.f_{2}\right)$ in a particular direction from spectral analysis of motions (either ambient noise or driven by minor earthquakes) recorded by an installed seismometer.

5. Calculate the soil spring properties. For the equivalent foundation radius,

$$
r_{o}=\sqrt{\frac{\text { cross-sectional area of building }}{\pi}}
$$

For the soil shear modulus, $G_{\text {soil }}=V_{s}^{2} \rho_{\text {soil }}$. For the soil translational spring stiffness,

$$
K_{T}=\frac{32(1-v)}{7-8 v} G_{\text {soil }} r_{o}
$$


For the soil rotational spring stiffness,

$$
K_{R}=\frac{8 G_{\text {soil }} r_{o}^{3}}{3(1-v)}
$$

6. Calculate the building properties. For the effective shear modulus, $G^{*}=\rho_{\text {building }}\left(4 L f_{1}\right)^{2}$.

The stiffness ratio $r$ and the effective Young's modulus of the building $E^{*}$ (through Equation 2) can be approximated from the defined parameters and the measured natural frequency ratio $f_{2} / f_{1}$ using the characteristic equation (Equation A26 in the online Appendix) or precalculated frequency ratio plots (e.g., Figures 4-5).

7. The constructed Timoshenko beam model provides natural frequency ratios $f_{i} / f_{1}$ as well as the corresponding mode shapes, where $f_{i}$ is the ith mode frequency and $f_{1}$ is the fundamental mode frequency. Higher mode frequencies can be estimated from the measured fundamental natural frequency. From the numerical method for solving the differential equations, the maximum estimated natural frequency is bounded by the following condition:

$$
f_{\text {max }}^{2}<\frac{k G A}{(2 \pi)^{2} \rho_{\text {building }} I}
$$

(see the online Appendix).

\section{EXISTING STRUCTURE ANALYSIS: MILLIKAN LIBRARY}

Caltech's Millikan Library (Figure 7) is a nine-story reinforced-concrete building with one level of basement embedded in stiff soil whose shear wave velocity is about $300 \mathrm{~m} / \mathrm{s}$. The building has moment-resisting frames and a very stiff core wall in both the NS and EW directions. It also has continuous NS shear walls that extend from the foundation to the roof on the east and west sides. The library is an unusually stiff building considering its height.
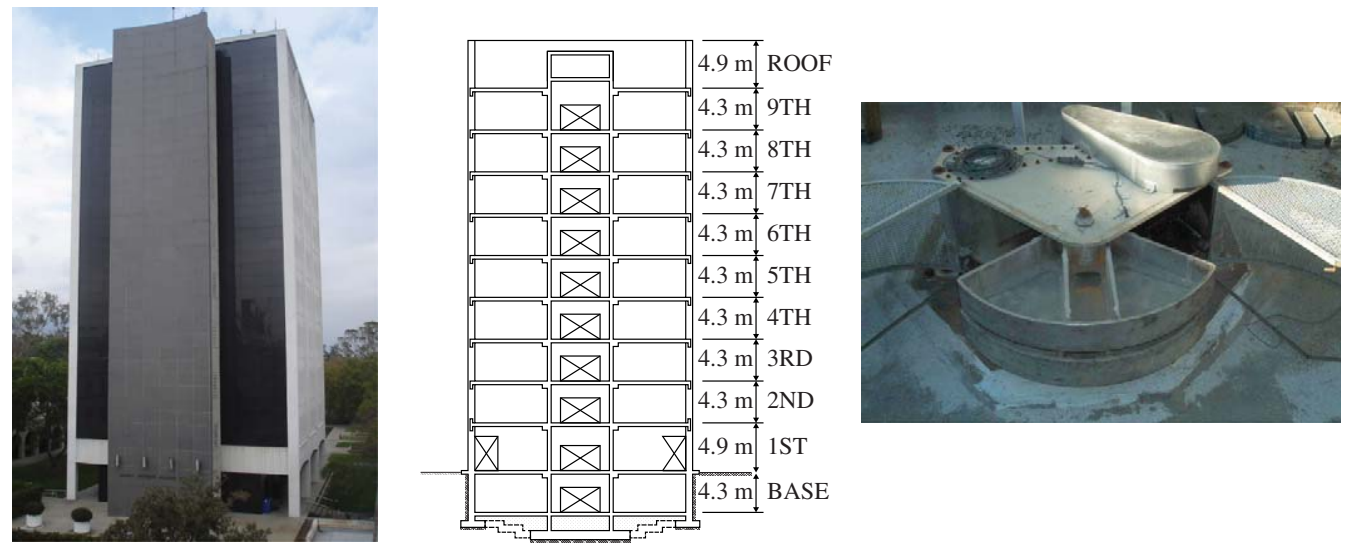

Figure 7. Millikan library profile and shaker on roof (from Bradford 2006). 
It was instrumented when first constructed in 1966, so it is possible to compare the apparent modal frequencies that have been recorded for many earthquakes and shaking experiments. Furthermore, a 36-channel accelerometer network recorded by a Kinemetrics Mt. Whitney system was installed in 1998; this is a triggered system that measures horizontal motions on every building level including the basement and the roof. An almost continuous recording of building motions has been available since 2000, when the Southern California Seismic Network installed the station MIK on the ninth floor. In 2008, a three-axis rotational sensor was added to MIK and a second identical station, MIKB, was installed in the basement.

A Kinemetrics harmonic shaker was installed on the roof of the library in the early 1970s, and it has been used for many class projects and research studies over the past decades (Figure 7); its maximum frequency is $9 \mathrm{~Hz}$. From forced-vibration experiments, the first two measured NS modal frequencies are 1.75 and $7.21 \mathrm{~Hz}$ (Bradford 2006), corresponding to natural frequency ratios of 1 and 4.1. The third NS mode has not yet been identified, and its frequency is almost certainly higher than the $9-\mathrm{Hz}$ limit of the roof shaker. The first two measured EW modal frequencies are 1.22 Hz and 4.76 Hz (Bradford 2006), corresponding to natural frequency ratios of 1 and 3.9. An apparent resonance at $7.83 \mathrm{~Hz}$ was suggested by Bradford (2006) to be the third EW mode. However, because that mode shape is not orthogonal to the other two mode shapes, only the first two identified EW modes are considered in this paper.

Table 3 shows the parameters used to construct the Timoshenko beam model for the library. Values for soil properties and building properties are extracted from Favela (2004) and Todorovska (2009). The calculated stiffness ratio $r$ is 27 and 17 for the NS and $\mathrm{EW}$ directions, respectively. The frequency ratios $f_{2} / f_{1}$ are similar for both directions, which means that the shear stiffness relates in the same way to the flexural stiffness for both directions. Using the Timoshenko beam model, the estimated third vibration mode occurs at $15.3 \mathrm{~Hz}\left(f_{3} / f_{1}=8.75\right)$ and $10.05 \mathrm{~Hz}\left(f_{3} / f_{1}=8.24\right)$ for the NS and EW directions, respectively. These values are definitely higher than the $9-\mathrm{Hz}$ safety limit of the roof shaker, so they have not been identified.

Figures 8 and 9 show the estimated mode shapes. Those produced from the Timoshenko beam are good estimations of the measured shapes. The frequency ratios $f_{2} / f_{1}$ of 3.9 and 4.1 occur between that of a pure shear beam and a pure bending beam. In such a case, the mode shapes of the Timoshenko beam provide a much better result compared to those of a pure shear beam. The two estimated third mode shapes from the Timoshenko beam are also shown in the figures.

\section{DISCUSSION}

Simple models of buildings represented as shear beams have been surprisingly successful. They can be used to explain many features of building modes of vibration, and they can aid understanding of traveling waves in a building (e.g., Kohler et al. 2007, Rahmani and Todorovska 2013). However, there are cases where buildings exhibit global bending about their base (tall and slender buildings that are stiff), and there are cases in which a better understanding of the effect of foundation rocking is desired. All of these effects are incorporated in the present solution for a cantilevered Timoshenko beam on a translational as well as a rotational spring. The good news is that the solution is expressible in a closed-form way 
Table 3. Timoshenko beam model parameters for Millikan Library

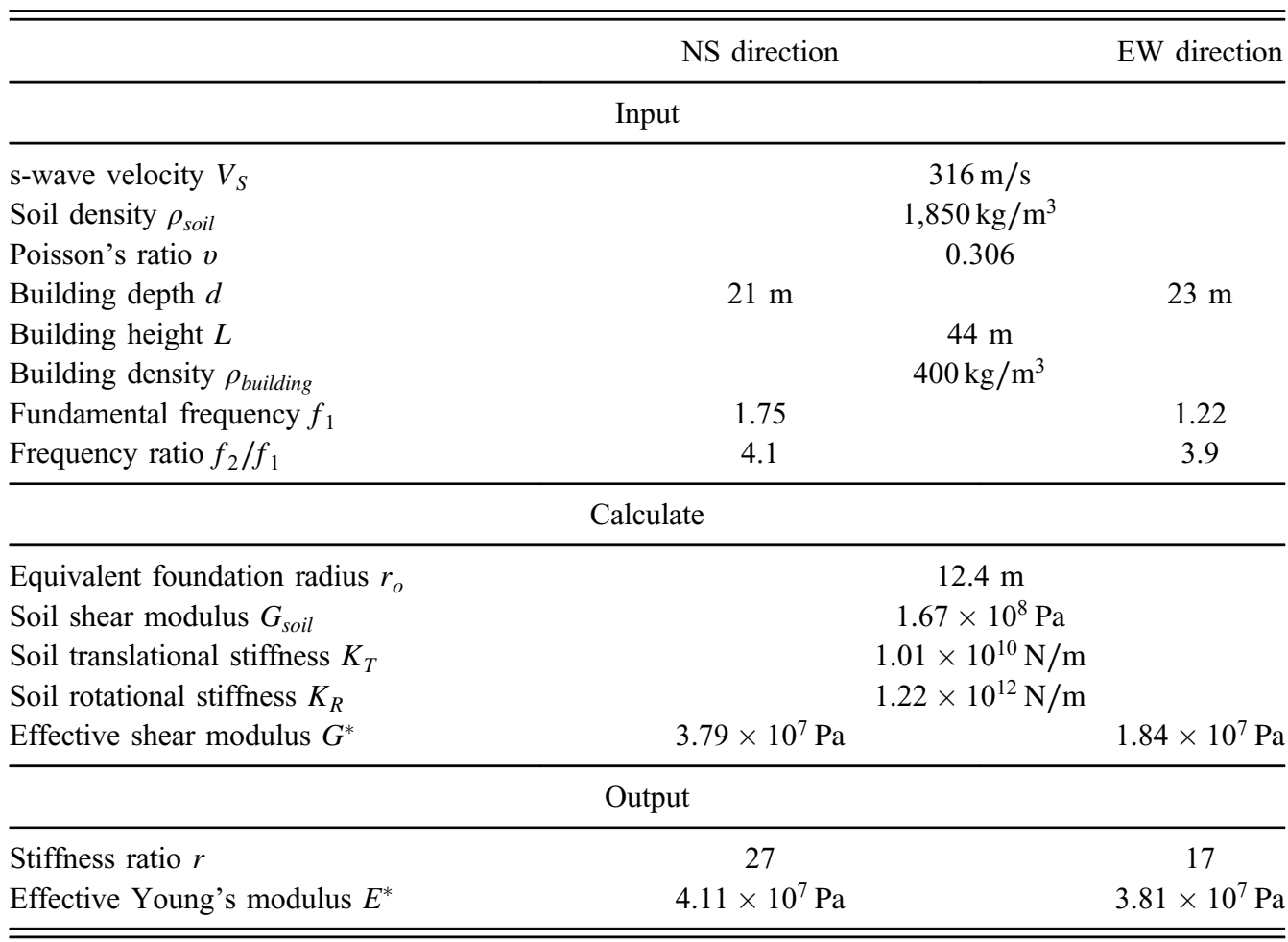

(see Equations A18 and A19 in the online Appendix). Unfortunately, the expressions are far more complex than for a simple shear beam.

The formal methodology presented here produces the mode shapes of a building assuming that (1) records are available from at least one seismometer in the building from which the first two modal frequencies in a given direction can be determined; (2) the exterior dimensions of the building can estimated; and (3) the building can be approximately modeled as a Timoshenko beam on a translational and rotational base. Of course the last assumption is both critical and dubious. Few buildings are really prismatic; it is common to design tall buildings with larger structural elements in the lower stories (they also have larger effective densities). Miranda and Taghavi (2005) investigated the effect of linear and parabolic variations of lateral stiffness along the building height using finite-element models. They suggested that the effect of nonuniform stiffness on mode shapes and frequency ratios is very small and can be neglected for bending-type structures. The individual effect on shear-type structures is greater, but the overall influence is relatively small and can be neglected. Nevertheless, we have shown that this simple methodology does predict the type of mode shapes of a building that has significant bending (e.g., Millikan Library).

Knowing the earthquake response from one sensor on a particular floor of a building can allow estimating responses for the other floors using the calculated mode shapes through modal decomposition (Kohler et al. 2013). In addition, the Timoshenko beam model can 


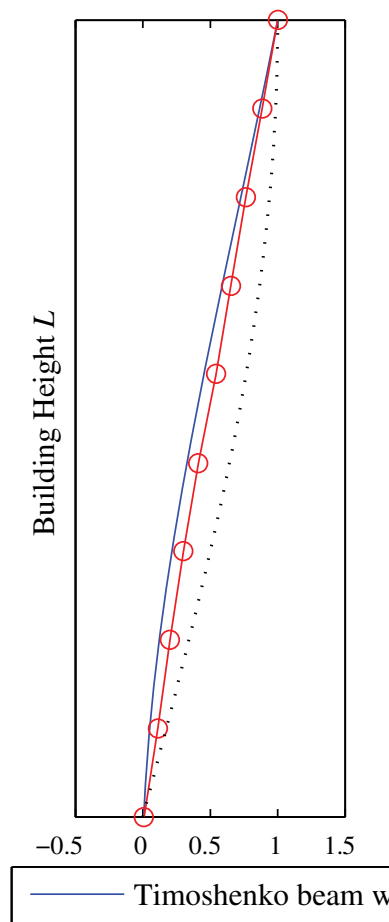

(a)

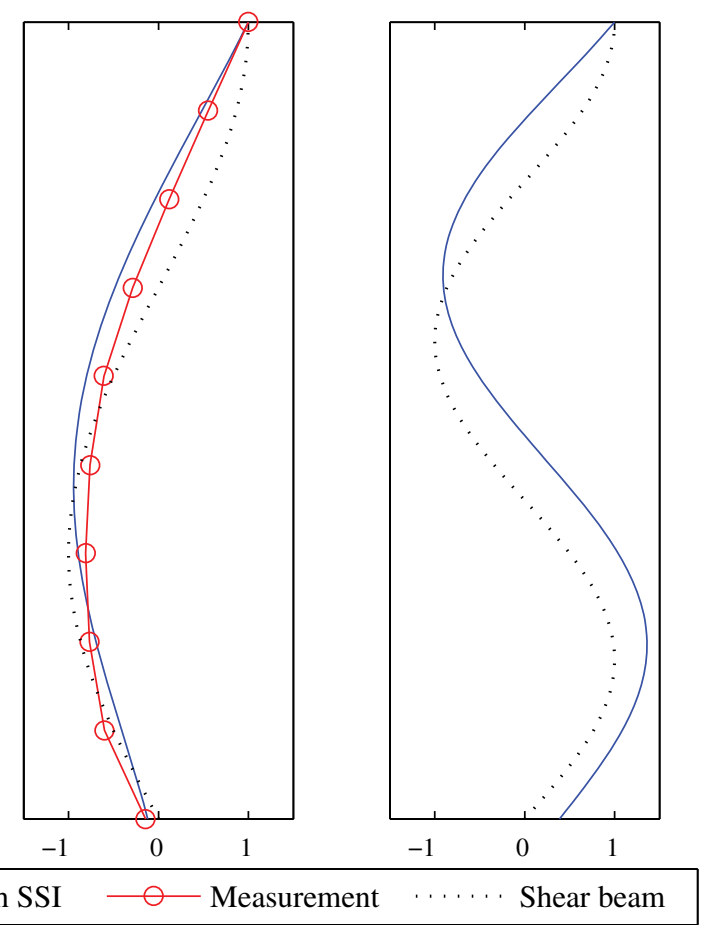

(c)

Figure 8. Mode shapes comparison for the Millikan library in the NS direction: (a) 1st mode, (b) 2nd mode, (c) 3rd mode.

be used to estimate building responses for predicted ground motions. The time behavior of each mode can be determined by solving the problem of a linear single-degree-of-freedom oscillator with the appropriate frequency and damping (damping can be approximately obtained from spectral analysis of the data). With an appropriate participation factor for each modal response, a vector sum of the modes can be performed to find the entire building's approximate deformations and floor accelerations for the the ground motion. The result allows approximation of the performance of nonstructural elements (e.g., elevator, mechanical piping, etc.) due to large floor accelerations while the structure of the building remains elastic.

In practice, it may be best to estimate the approximate effect of foundation rocking by estimating the rocking stiffness from the soil's elasticity parameters and the building's footprint. For example, Bycroft (1956) presented the solution for a rigid circular disk that forced to rock on an elastic half-space. This approach is not pursued here, but if an independent estimate of rocking stiffness were available, the present solutions could be used to estimate the approximate building motions from estimates of the first two modal frequencies. This study focuses on buildings without significant plan irregularities and so torsional effects are ignored. Possible future studies can include the effect of three-dimensional seismic excitation and an extension of the existing Timoshenko beam model to capture the torsional 


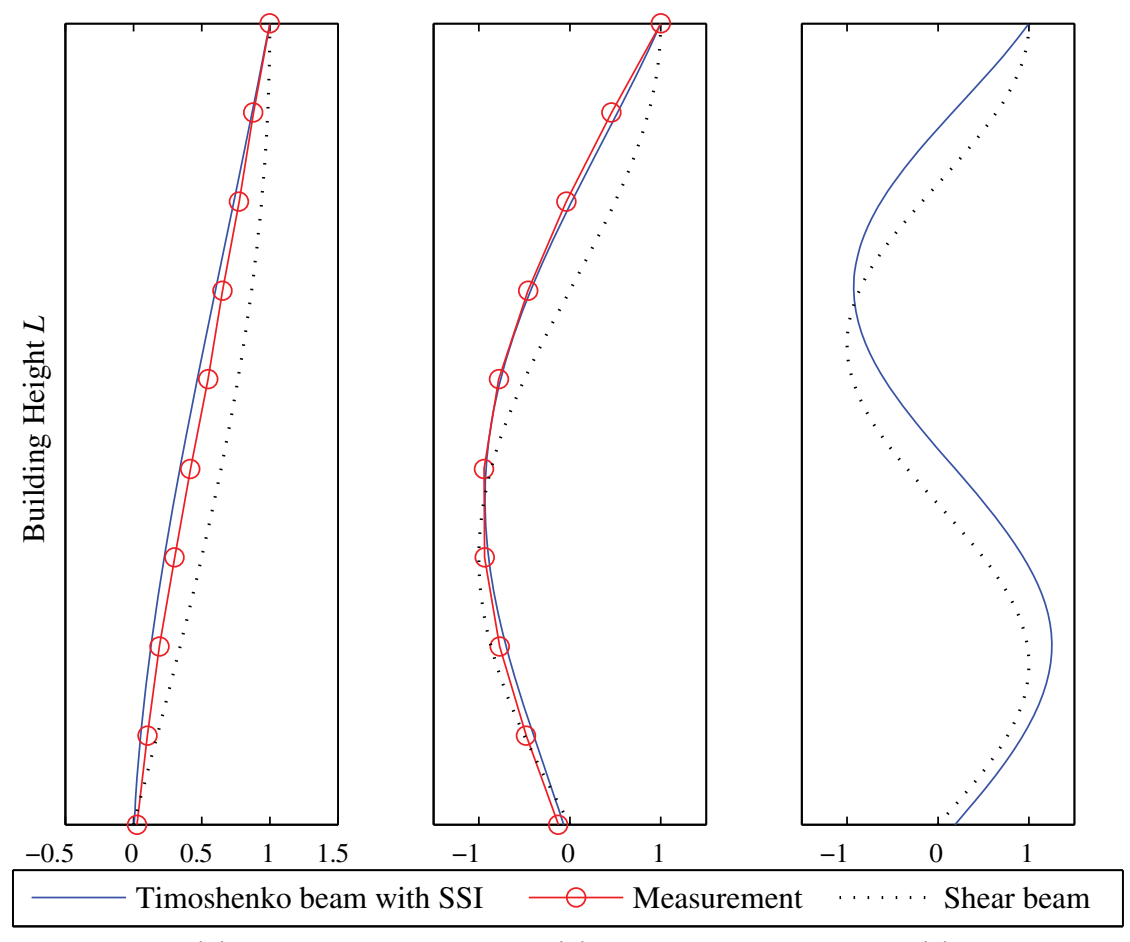

(a)

(b)

(c)

Figure 9. Mode shapes comparison for the Millikan library in the EW direction: (a) 1st mode, (b) 2nd mode, (c) 3rd mode.

responses of a tall building. Such analysis may require comparisons with three-dimensional finite-element simulations, but the procedure described should provide a good estimate of building motion and is relatively simple to apply. It is important, however, for any potential user to recognize that this type of analysis cannot produce detailed results.

\section{CONCLUSION}

In this paper, a closed-form solution for the prismatic Timoshenko beam model with soilstructure interaction is derived. Timoshenko beams with a small stiffness ratio $(r=0.1)$ behave similarly to pure shear beams whereas those with a large stiffness ratio $(r=1,000)$ and a high aspect ratio $(L / d=10)$ behave similarly to pure bending beams. The soil-structure interaction affects shear-type buildings, but the corresponding effect is small for bending-type buildings. In general, buildings behave like a Timoshenko beam with properties between a pure shear beam and a pure bending beam, so the soil-structure interaction should not be neglected in determining the dynamic behaviors of buildings during earthquakes.

A formal methodology is presented that predicts the mode shapes of a building, assuming that (1) records from at least one seismometer in the building are available from which the 
first two modal frequencies in a given direction can be determined, (2) the exterior dimensions of the building can be estimated, and (3) the building can be approximately modeled as a Timoshenko beam on a translational and rotational base. The proposed method is successfully applied to estimate the mode shapes of Millikan Library at Caltech.

\section{ACKNOWLEDGMENTS}

The authors thank Dr. Monica Kohler for her review of the manuscript and her valuable suggestions. This work is partially supported by the National Science Foundation (EAR-1027790), the George Housner Earthquake Engineering Research Endowment (EAS-41212), the Fred L. Hartley Family Foundation, and the Croucher Foundation. The support of these institutions is gratefully acknowledged.

\section{APPENDIX}

Please refer to the online version of this paper to access "Appendix: Derivation of the one-dimensional Timoshenko beam model with soil-structure interaction."

\section{REFERENCES}

Balendra, T., Chan, W. T., and Lee, S. L., 1982. Modal damping for torsionally coupled buildings on elastic foundation, Earthquake Engineering and Structural Dynamics 10, 735-756.

Bradford, S. C., 2006. Time-frequency analysis of systems with changing dynamic properties, Ph.D. Dissertation, California Institute of Technology, Pasadena.

Boutin, C., Hans, S., Ibraim, E., and Roussillon, P., 2005. In situ experiments and seismic analysis of existing buildings-Part II: Seismic integrity threshold, Earthquake Engineering and Structural Dynamics 34, 1531-1546.

Bycroft, R. N., 1956. Forced vibrations of a rigid circular plate on a semi-infinite elastic space and on an elastic stratum, Philosophical Transactions of the Royal Society of London. Series A, Mathematical and Physical Sciences 248, 327-368.

Clayton, R., Heaton, T., Chandy, M., Krause, A., Kohler, M., Bunn, J., Olson, M., Faulkner, M., Cheng, M. H., Strand, L., Chandy, R., Obenshain, D., Liu, A., and Aivazis, M., 2011. Community Seismic Network, Annals of Geophysics 54, 738-747.

Cochran, E. S., Lawrence, J. F., Kaiser, A., Fry, B., Chung, A., and Christensen, C., 2011. Comparison between low-cost and traditional MEMS accelerometers: A case study from the M7.1 Darfield, New Zealand, aftershock deployment, Annals of Geophysics 54, 728-737.

Dym, C. L., and Williams, H. E., 2007. Estimating fundamental frequencies of tall buildings, Journal of Structural Engineering 133, 1479-1483.

Favela, J., 2004. Energy Radiation From A Multi-Story Building, Ph.D. Dissertation, California Institute of Technology, Pasadena.

Foutch, D. A., and Jennings, P. C., 1978. A study of the apparent change in the foundation response of a nine-story reinforced concrete building, Bulletin of the Seismological Society of America 68, 219-229.

Gajan, S., Raychowdhury, P., Hutchinson, T. C., Kutter, B. L., and Stewart, J. P., 2010. Application and validation of practical tools for nonlinear soil-foundation interaction analysis, Earthquake Spectra 26, 111-129 
He, X., and Tromp, J., 1996. Normal-mode constraints on the structure of the Earth, Journal of Geophysical Research 101, 20053-20082.

Heidebrecht, A. C., and Smith, B. S., 1973. Approximate analysis of tall wall-frame structures, Journal of the Structural Division, Proceedings of the ASCE 99, 199-221.

Hsu, J. C., Lee, H. L., and Chang, W. J., 2007. Flexural vibration frequency of atomic force microscope cantilevers using the Timoshenko beam model, Nanotechnology 18, 28.

Iwan, W., 1997. Drift spectrum: Measure of demand for earthquake ground motion. Journal of Structural Engineering 123, 397-404.

Jennings, R. L., and Newmark, N. M., 1960. Elastic response of multi-story shear beam type structures subjected to strong ground motion, in Proceedings of the Second World Conference on Earthquake Engineering, Vol. 2, Science Council of Japan, Tokyo, 699-717.

Kohler, M. D., Davis, P. M., and Safak, E., 2005. Earthquake and ambient vibration monitoring of the steel frame UCLA Factor building, Earthquake Spectra 21, 715-736.

Kohler, M. D., Heaton, T. H., and Bradford, S. C., 2007. Propagating waves in the steel, momentframe Factor building recorded during earthquakes, Bulletin of the Seismological Society of American 97, 1334-1345.

Kohler, M. D., Heaton, T. H., and Cheng, M. H., 2013. The community seismic network and quake-catcher network: enabling structural health monitoring through instrumentation by community participants, in Proceedings of SPIE 8692, 10-14 March 2013, San Diego, CA.

Krishnan, S., and Muto, M., 2013. Sensitivity of the earthquake response of tall steel moment frame buildings to ground motion features, Journal of Earthquake Engineering 17, 673-698.

Michel, C., Hans, S., Guéguen, P., and Boutin, C., 2006. In situ experiment and modelling of rc-structure using ambient vibration and timoshenko beam, in Proceedings of 1st European Conference on Earthquake Engineering and Seismology (ECEES), 3-8 September 2006, Geneva.

Miranda, E., 1999. Approximate seismic lateral deformation demands in multistory buildings, Journal of Structural Engineering 125, 417-425.

Miranda, E., and Taghavi, S., 2005. Approximate floor acceleration demands in multistory buildings-I: Formulation, Journal of Structural Engineering 131, 203-211.

Rahgozar, R., Safari, H., and Kaviani, P., 2004. Free vibration of tall buildings using Timoshenko beams with variable cross-section, in Proceedings of SUSI VIII, Crete, 233-242.

Rahmani, M., and Todorovska, M. I., 2013. 1D system identification of buildings during earthquakes by seismic interferometry with waveform inversion of impulse responsesmethod and application to Millikan Library, Soil Dynamics and Earthquake Engineering 47, 157-174.

Romanowicz, B. A., Panning, M. P., Gung, Y.-C., and Capdeville, Y., 2008. On the computation of long period seismograms in a 3-D earth using normal mode based approximations, Geophysical Journal International 175, 520-536.

Rosat, S., Watada, S., and Sato, T., 2007. Geographical variations of the 0S0 normal mode amplitude: predictions and observations after the Sumatra-Andaman earthquake, Earth Planets Space 59, 307-311.

Stewart, J. P., and Fenves, G. L., 1998. System identification for evaluating soil-structure interaction effects in buildings from strong motion recordings, Earthquake Engineering and Structural Dynamics 27, 869-885. 
Timoshenko, S., 1937. Vibration Problems in Engineering, $2^{\text {nd }}$ edition, Van Nostrand, Princeton, NJ.

Timoshenko, S., and Goodier, J. N., 1951. Theory of Elasticity, $2^{\text {nd }}$ edition, McGraw-Hill, New York.

Todorovska, M. I., 2009. Seismic interferometry of a soil-structure interaction model with coupled horizontal and rocking response, Bulletin of the Seismological Society of America 99, 611-625.

Wang, C. M., Zhang, Y. Y., and He, X. Q., 2007. Vibration of nonlocal Timoshenko beams, Nanotechnology 18, 10.

Westergaard, H. M., 1933. Earthquake-shock transmission in tall buildings, Engineering News Record III, 654-656.

(Received 16 January 2013; accepted 9 September 2013) 